Nig. J. Biotech. Vol. 36 (2) : 167-187 (Dec 2019)

ISSN: 01891731

Available online at

http://www.ajol.info/index.php/njb/index

and www.biotechsocietynigeria.org

DOI: https://dx.doi.org/10.4314/njb.v36i2.17

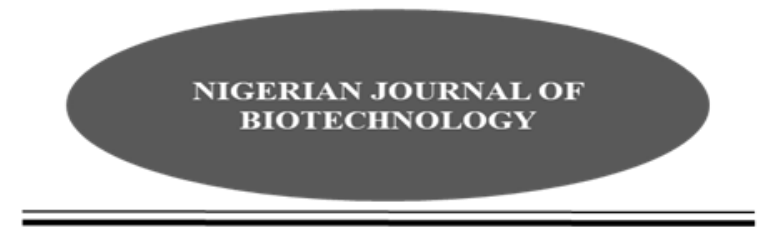

\title{
Analysis of differentially expressed genes induced by drought stress in tef (Eragrostistef) root
}

\author{
Hewan Demissie Degu \\ Hawassa University College of Agriculture, School of Plant and Horticulture Science, Plant Biotechnology
}

\begin{abstract}
Drought stress is one of the major abiotic stresses which induces root growth in tef. Molecular mechanisms underlying the elongation of roots under drought stress are not known. Therefore, we aimed to study the tef root system to uncover the expression profiles for drought stress using Agilent gene chip of rice. One hundred seventy-five expressed genes were found to be differentially expressed after eight days of drought stress with Eragrostis tef- resistant genotype, Kaye Murri. The drought-responsive genes were isolated and classified into nine categories according to the functional roles in plant metabolic pathways, such as defense, signal transduction, cell wall fortification, oxidative stress, photosynthesis, development, cell maintenance, RNA binding, and unknown functions. The profiles of tef root genes, responsive to drought stress shared common identities with other expression profiles known to be elicited by diverse stresses, including pathogenesis, abiotic stress, and wounding. Well-known drought-related transcription factor-like, WRKY and bHLH were upregulated. Cell transport-related regulators such as potassium transporter 22-like, auxin transporter-like protein 1 , and wall-associated receptor kinase were also involved in the expression profile of tef root under drought stress. Their expression had enhanced the drought-responsive genes, which, have a direct role to maintain root growth under drought stress.
\end{abstract}

Key words: Drought, Genome, Microarray, Root, Tef

Corresponding authors contact: hewan.dd@gmail.com; Tel.: +251-932243391

\section{Introduction}

Drought stress has been reported as one of the serious threats to staple crops, including Eragrostis tef (Abraha et al., 2016). It causes tremendous economic losses in tef production to the amount of approximately $\$ 21.3$ million annually in Ethiopia. Drought basically affects the growth of root, which limits nutrient and water absorption. Therefore, researches that help to understand the mechanism of root elongation under drought stress have got increased attentions in order to breed crop plants that cope up drought stresses.
Due to its allotetraploid chromosome structure, tef is one of the least plastic plant species in terms of adaptation. However, the plant is capable of growing at high and low altitudes in tropical and subtropical climates. Eragrostistef plant has acquired a myriad of developmental and metabolic strategies to optimize water uptake. It also efficiently balances this with water utilization during vegetative growth and reproduction (Haile sillasie et al., 2016).

In the past, a few researches have been done to unravel the molecular processes of droughtinduced regulations of tef root (Abraha et al., 
2016; Admas and Belay, 2011; Assefa et al., 2011; Belay et al., 2008, 2009). Studies on shoot physiologyhave shown that sugars, sugar alcohols, amino acids, and amines function as osmolytes, protecting cellular functions from the effects of dehydration, and are known to accumulate under drought stress (Ayele, 1999 and Degu et al. 2008). Reduction in vegetative growth, stomatal closure and a decrease in the rate of photosynthesis (Admas and Belay 2011; Degu et al. 2008) are among the earliest responses of tef to drought, protecting the plant from extensive water loss.

Researchers have also identified that there are extensive genetic diversities in the physiological and root length of tef. This genetic variability has been exploited to produce locally adapted drought-tolerant tef cultivars for the dry tropical areas of Ethiopia (Plaza et al., 2013). The morphology of tef primary root and elongation at low water potentials have been studied (Degu et al. 2008) and QTL's affecting root length mapped (Degu and Fujimura, 2010). However, the expression patterns of root growth to waterdeficit have not been sufficiently characterized.

Currently, plant science has entered a new era following the completion of the entire genomic sequence of Arabidopsis and rice (Oryzasativa). Researchers are using model plants to identify the specific functions of plant genes and their expression profiles. The genome, transcriptome, proteome and metabolome tools are used to analyze root system. The result of the transcriptome analysis vary based on the experimental setups, the different germplasm, and accessions used. Thus, there are different transcripts which describe the response of plant roots towards drought stress.

Focusing on tef, one transcriptome characterizations of tef plant in response to 1week of drought showed 23 and 15 differentially expressed transcriptome (Cannarozzi et al., 2014). The study suggests changes in energy (B-glucanase and ERD), salt-sensitive enzymes (SAL1) and chloroplast regulation (stay-green gene -SGR). This implies that there is a need to study how the root is regulated, and to understand the different transcriptome changes which contributed to the growth and elongation of root length under drought stress.
Rice is a model cereal crop to study the stress response at a molecular level due to the availability of whole-genome information and other molecular tools. Tef is one of the most drought-tolerant cereals, providing a useful platform to understand tolerance mechanisms. Besides, the genome of monocots are characterized by high synteny, and it is feasible to use rice chips to do hybridization with tef RNAs. In the present work, genome-wide transcriptional characterization of tef roots in response to drought deficiency is presented.

Identifying drought-responsive genes in the root, and the understanding of their function can lead to a better breeding of crop plants under drought stress. We applied microarray platforms to identify candidate genes that are associated with a phenotype of drought resistance in tef. The work plan applied the existing rice microarray technology created by the National Agricultural Research Organization of Ethiopia , and tests the feasibility of the orthologou arrays for use in multiple crops. The proposed project will enhance knowledge towards the elucidation of gene function in seminal root elongation under drought stress. Thus, the present study was planned to make a comparative study of drought responsiveness in drought and wellirrigated tef exploring the availability of wholegenome level information and molecular tools in rice.

\section{Materials and Methods}

\section{Plant Material and Growth Conditions}

The late-maturing improved variety of tef cv. Kaye Murre was used in the study. KayeMurre is capable of elongating its roots under drought stress (Degu and Fujimura, 2010). The seeds were obtained from Debreziet Agricultural Research center of Ethiopia. The seeds were surface sterilized and germinated on filter paper at $25^{\circ} \mathrm{C}$ in the dark. After 3 days, seedlings with seminal roots about $1 \mathrm{~cm}$ long were transplanted to a plastic root box $(30 \mathrm{~cm}$ in width; $25 \mathrm{~cm}$ in diameter and $24 \mathrm{~cm}$ in height) containing (1) horticulture nursery soil (Kureha Ltd., Tokyo, Japan); with holes at the bottom. Horticulture nursery soil was porous, consisting of uniformly sized soil particles $(0.5-3.0 \mathrm{~mm})$, and containing $0.4 \mathrm{~g} \mathrm{~kg}-1$ of nitrogen, $1.9 \mathrm{~g} \mathrm{~kg}-1$ 
of phosphorus, $0.6 \mathrm{~g} \mathrm{~kg}-1$ of potassium, and 0.2 $\mathrm{g} \mathrm{kg}-1$ of magnesium. The liquid fertilizer was composed of nitrogen: phosphorus: potassium at the rate of $2: 1: 1$. The growth conditions were $12 / 12 \mathrm{~h}$ day/night, one light period supplied 820 $\mu \mathrm{mm}-2 \mathrm{~s}-$ photosynthetically active photon flux density (PPDF), $30 / 20^{\circ} \mathrm{C}$ (day/night); and temperature with RH 60 to $70 \%$. For the control experiment, plastic root boxes were placed in tanks for a continuous supply of water through the root system. However, for drought stress treatment, root boxes were kept on a separate tank without the supply of water.

\section{Soil, root and leaf water content measurement}

Gravimetric soil water content was determined as described by Singh, \&Baghini (2014). A soil sample was taken from three points within the plastic basket (both sides and a center) with a borer, and the collected soil was stored in a 1.5$\mathrm{ml}$ Eppendorf tube to equilibrate soil moisture for $2 \mathrm{~h}$. The water content was measured by using electric balance before and after drying the soil in the oven for 48 hrs. The measurement was replicated three times, and the data were averaged. Soil, leaf and root water potential were measured by using a dew point micro voltmeter (model HR33T, WESCOR, Inc. Logan, UT). First, the soil sample was taken using a borer ( $5 \mathrm{~mm}$ in diameter). The collected soil was stored in $1.5 \mathrm{ml}$ Eppendorf tube to equilibrate to the surrounding environment for 2 hrs. Similarly, root sample and leaf sample were taken and kept in $1.5 \mathrm{ml}$ Eppendorf tube.

For relative water content (RWC), two leaves per plant were cut and stored in Eppendorf tube on ice. The fresh weight (FW) was measured following immersing it in double-distilled water (DDW) for 8 hours. This was followed by measuring the turgid weight (TW). The sample was then oven-dried for 24 hrs at $80^{\circ}$ centigrade, and dry weight (DW) was measured after cooling it to 50 centigrade. RWC is calculated using the following formula;

$$
\text { RWC }=\frac{F W-D W}{T W-D W} \times 100
$$

For osmotic potential (OP) measurement, leaf and root samples (about $1.5 \mathrm{~cm}$ ) were collected at $0,2,4,6$ and 8 days after drought stress treatment, and were kept in Eppendorf tube at -
$20 \circ$ centigrade. During measurement, the samples were withdrawn from $-20^{\circ}$ centigrade and left at the room temperature to thaw. The Eppendorf was centrifuged at $14000 \mathrm{~g}$ for 15 minutes. The sap was measured by a dew point micro voltmeter (model HR33T, WESCOR, Inc.). Osmotic adjustment (OA) was calculated as the difference between the measured and expected concentration-effect OP of the drought stressed plants. For analysis of the transcription under drought stress, seminal root tips $(1 \mathrm{~cm})$ were harvested after 8 days of drought stress from the well-irrigated and drought-stressed sample. All samples were collected at noon. After harvesting, samples were immediately placed in liquid nitrogen and stored at $-80^{\circ} \mathrm{C}$ until RNA extraction.

\section{MicroArray experiments}

The Microarray experiment was done following the standard procedure (Figure 1). Total RNAs were extracted from tef root using the RNeasy Maxi kit (Qiagen, Valencia, CA, USA). The RNA samples were treated with DNase I (NipponGene, Chiyoda-ku, Tokyo, Japan) and quantified by spectrophotometer using Nano Drop $^{\text {TM }} 1000$ Thermo Scientific. The RNA quality was checked using the Agilent BioAnalyzer. Next, poly (A) + RNA was isolated from $200 \mu \mathrm{g}$ of total RNA using an mRNA isolation system (Nippon- Gene, Japan). Linear amplification and labeling were carried out with fluorescent linear amplification kit (Agilent). Transcriptional analysis was carried out using a 22 mer-oligo chip from the Agilent Technologies produced by the Plant Functional Genomics Center, National Institute of Agricultural Science of Japan. The chip (Catalogue array- GA4138A) carries 21,000 genes from the genome of Oryza sativa L. spp. Japonica (Nipponbarre). Redundant probes were randomly distributed in triplicate across the array, each comprising a 22-mer oligonucleotide designed using inkjet-based technology which prints DNA on 1X 3" glass slide. The source of sequence information included a range of genes that can measure the expression of drought, salt and cold stress genes for rice and related plants(Sato et al., 2013). A complete description of the chip is available at the Rice Expression Profile Database (RiceXPro). Three biological replicates per treatment were analyzed. Four (4) microgram of labeled cDNA was hybridized to 
the array according to the manufacturer's recommendations (Maruyama et al., 2014). The array was scanned with the Agilent DNA microarray scanner, and the expression data were extracted with the Agilent Feature Extraction software.

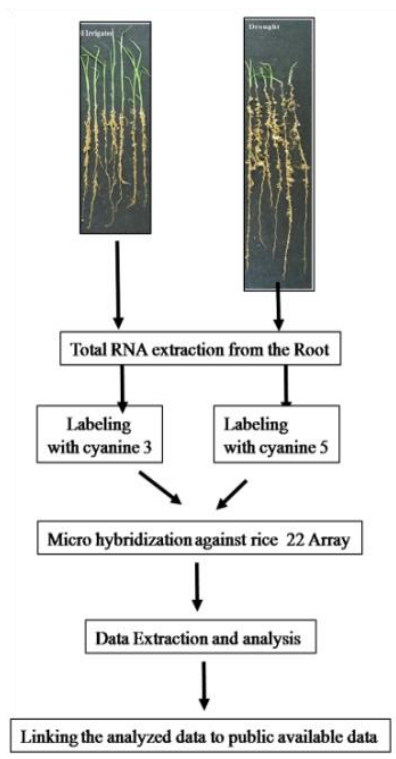

Figure 1. Experimental set up and hybridization of rice microarray on tef cDNA.

\section{$R T-P C R$}

Aliquot of total RNAs $10 \mu \mathrm{g}$ RNA was reverse transcribed and used to synthesize singlestranded CDNA using the First-strand CDNA synthesis kit (TAKARA SHUZO CO. LTD., Otsu, Shiga, Japan) according to the manufacturer's instructions. RT-PCR reactions were performed with the Access RT-PCR kit (Thermo Fisher Scientific Inc) according to the manufacturer's protocol. The sequences of the primer were (FW=CGAGCGCTCCAACTCATC and RW $=$ CAGCACCGAGCTGTCCTC with annealing temperature $60^{\circ} \mathrm{C}$. The amplicon size was 500 bp); WRKY gene fragments were then amplified using gene-specific primers. Gene expression patterns were normalized to the expression of the 18S ribosomal RNA (FW = AACGGCTACCACATCCAAGG, and RW = TCATTACTCCGATCCCGAAG). The PCR consisted of 40 cycles ( $30 \mathrm{~s}$ at $94^{\circ} \mathrm{C}, 1 \mathrm{~min}$ at $60^{\circ} \mathrm{C}$, and $1 \mathrm{~min}$ at $\left.72^{\circ} \mathrm{C}\right)$. The PCR-products were sequenced with (Macrogen, Korea).

Expression patterns of WRKY using real timeQuantitative-PCR
Quantitative PCR were carried out by designing primer using "Primer 3" software

(http://frodo.wi.mit.edu/primer3/) according to the following criteria: melting temperature: $59^{\circ} \mathrm{C}$ primers' length: 18-24 nucleotides, product size: 110 base pairs (bp) and GC content: $40-55 \%$. Quantitative PCR was performed using CDNA made of $50 \mathrm{ng}$ total RNA, with an Absolute QPCR SYBER Green ROX kit (Thermo Scientific, ABgene UK), using Rotor-Gene 6000 (Corbett life Sciences, Australia). Samples were first heated for $15 \mathrm{~min}$. at $95^{\circ} \mathrm{C}$ followed by 40 PCR cycles of $10 \mathrm{~s}$ at $95^{\circ} \mathrm{C}, 15 \mathrm{~s}$ at $59^{\circ} \mathrm{C}$ and $20 \mathrm{~s}$ at $72{ }^{\circ} \mathrm{C}$. Negative controls had no cDNA. Gene expression patterns were normalized to the expression of the QuantumRNA ${ }^{\mathrm{TM}}$ Classic $18 \mathrm{~S}$ Internal Standard (Thermo Scientific, ABgene UK). The fold change is calculated according to the following formula.

Ratio target gene in Drought Stress/Irrigated control $=\frac{\text { Fold change in target gene }}{\text { Fold change in Reference gene }}$ 


\section{Northern Blot Analysis}

Root samples were harvested at mid-day in 4, 6 and 8 days of drought-stressed sample, and were frozen in liquid nitrogen and then stored at $-80^{\circ} \mathrm{C}$ until further use. Total RNAs were extracted using the RNeasy Maxi kit (Qiagen, Valencia, CA, USA). Samples were treated with DNase I (NipponGene, Chiyoda-ku, Tokyo, Japan) and quantified by spectrophotometer using Nano Drop ${ }^{\mathrm{TM}} 1000$ Thermo Scientific. A $10 \mu \mathrm{g}$ aliquot of total RNA in a volume of $3.3 \mu \mathrm{l}$ was denatured by incubation with $1.5 \mu \mathrm{l}$ of $6 \mathrm{M}$ glyoxal, $1.2 \mu \mathrm{l}$ of sodium phosphate buffer $(0.1$ $\mathrm{M}, \mathrm{pH} 7.0$ ) and $6 \mu \mathrm{l}$ of dimethylsulfoxide (DMSO) at $55^{\circ} \mathrm{C}$ for $1 \mathrm{~h}$. The RNA solution was chilled on ice, and was separated by electrophoresis through a $1.2 \%$ agarose gel with $10 \mathrm{mM}$ phosphate buffer. Afterwards, the RNA was transferred onto a Hybond $\mathrm{N}+$ membrane (Amersham Biosciences), and was probed with [a-32P] dCTP-labeled DNA using the BCA Best labeling kit (Takara) according to the manufacturer's instructions in hybridization buffer [5× SSPE (SSPE is0.15 M NaCl, $10 \mathrm{mM}$ sodium phosphate, 1 mM EDTA), 1× Denhalt'ssolution, $0.1 \%(\mathrm{w} / \mathrm{v})$ SDS and $2 \mathrm{ng} \mathrm{ml}$ 1 DNA solutions from salmon sperm (Nippon gene)] for $24 \mathrm{~h}$ at $60^{\circ} \mathrm{C}$. The blots were washed once in $2 \times$ SSC (20x SSC is $3 \mathrm{M} \mathrm{NaCl}$ and 300 $\mathrm{mM}$ trisodium citrate) for $5 \mathrm{~min}$ at room temperature, once with $2 \times \mathrm{SSC}, 0.1 \%(\mathrm{w} / \mathrm{v})$ SDS for $15 \mathrm{~min}$ at $60^{\circ} \mathrm{C}$, once with $1 \times$ SSC, $0.1 \%(\mathrm{w} / \mathrm{v}) \mathrm{SDS}$ for $15 \mathrm{~min}$ at $60^{\circ} \mathrm{C}$ and lastly with $0.1 \times \mathrm{SSC}, 0.1 \% \mathrm{SDS}(\mathrm{w} / \mathrm{v})$ for $15 \mathrm{~min}$ at $60^{\circ} \mathrm{C}$.Autoradiography was performed at $-80^{\circ} \mathrm{C}$ using BioMax film (Kodak, Rochester, NY, USA) with an intensifying filter. The band intensities were quantified by using 'ImageJ' software (http://rsb.info.nih.gov/ij/)

\section{Statistical Analysis}

Analysis of variance and mean separation by Fisher's least significant difference methods were performed using Agricolae package with the statistical $\mathrm{R}$ programming language. Analysis of microarray raw data was performed using the open-source software of the Bioconductor project (Smyth et al., 2005) with the statistical $R$ programming language ( $R$ Core Team 2018). Background adjustment, summarization and quintile normalization were performed using the limma package (Ritchie et al., 2015). Differentially expressed probes were identified by linear models' analysis (Ritchie et al., 2015) using limma package by applying Bayesian correction, an adjusted p-value of 0.05 and an absolute fold change $|F C| \geq 2$. Functional annotation and physical location of the genes represented by the probe sets in the japonica genome were obtained from the Rice XPro website (McCouch, Symbolization, Linkage, \& Cooperative, 2008). Genes were grouped into main functional categories according to the "biological" terms of the Gene Ontology (Mi et al., 2016) assigned to each rice EST (Release 12.0) based on the results of BlastP analysis against the UniProt database. Genes without significant BlastP results were classified as "Unknown"; Evalue < 1e-8; identity > 40\%.

\section{Results}

Morphological change of tef root tip responding to drought stress

Drought stress induced the elongation of the seminal root in tef in accelerated fashion (Figure 2 ). The root lengths for plants placed under drought stress were $33.3 \%$ longer when compared to the well-irrigated sample. In terms of RWC and leaf water potential, there was no significant difference between drought-stressed and well-irrigated samples (Table 1). And the number of leaves were the same for both drought-stressed and well-irrigated control plants (Figure 2). The only difference was the shoot length, where there was accelerated plant height for irrigated control plants (Figure 3). However, there were significant differences between the two treatments in terms of soil and root water potential. Where the root water potential reduced to $-1.2 \mathrm{MPa}$ for droughtstressed sample, it remained $-0.4 \mathrm{MPa}$ for wellirrigated tef sample (Table 1). This indicates that when the drought stress increased, the available water content for the root was about $40 \%$ at field capacity. The available water content at field capacity was about $80 \%$ for well-irrigated control plants. This indicates clear water stress has been created in the drought-stressed sample. 


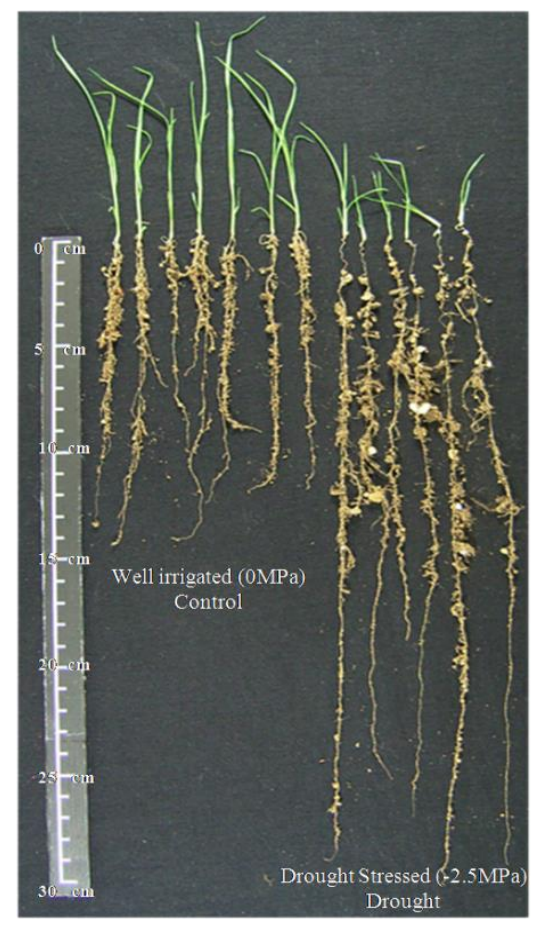

Figure 2. Shoot and root growth of E. tef at the indicated days after irrigation stopped . Root elongation of E. tef for the control (left) and drought (right) treatment at 0 and 2.5MPa of water potential.

However, OP for the drought-stressed plants was significantly lower than the well-irrigated control sample (Table 1). Specifically, the OA was the highest as the day for drought stress increases, and showed a significant difference between drought stressed and well irrigated samples. In the shoot, OA was the highest when compared to the root. The measured value was $0.05 \mathrm{MPa}$ in control and $0.98 \mathrm{MPa}$ in droughtstressed samples, respectively. It is important to note that compared to root under drought stress, the shoot exhibited lower OA, while the decrease in the RWC was significantly different, and it was the lowest for the root (Table 1).

Similarly, after 8 days of drought stress, the soil water potential for the control was about -0.5 $\mathrm{MPa}$ while it became $-1.5 \mathrm{MPa}$ under drought stress. Even though the soil water potential was significantly different between the control and stressed samples, the leaf water potential measurement and analysis showed no significant difference between the two treatments (Table 1 ). This was also confirmed by the nonsignificant difference between the two treatments on the relative water content.
However, the root water potential was significantly different between the two treatments (Table 1). The effect of different water potential between the soil, root, and shoot was revealed on the shoot and root growth (Figure 2). Significant difference $(p \leq 0.05)$ was observed for the shoot and root growth among the control and stressed plants of tef. Although there was a delay in the shoot growth under drought stress, seedlings maintained a healthy green color after 192 hrs of drought stress (Figure 2). On the other hand, there was no significant difference in leaf water potential for both control and drought-stressed plants. (Table 1). 
Hewan/ Nig. J. Biotech. Vol. 36 Num. 2 : 167 - 187 (December 2019)

Table 1. Relative water contents (RWC), osmotic potential (OP), and osmotic adjustment (OA) in shoot and root after stopping irrigation.

\begin{tabular}{|c|c|c|c|c|c|c|c|}
\hline & \multirow{2}{*}{$\begin{array}{l}\text { Days after } \\
\text { water } \\
\text { withholding }\end{array}$} & \multicolumn{3}{|c|}{ Control } & \multicolumn{3}{|c|}{ Stress } \\
\hline & & RWC(\%) & OP (Mpa) & OA (Mpa) & RWC(\%) & OP(Mpa) & OA(Mpa) \\
\hline \multirow{6}{*}{ Shoot } & 0 & $97.6 \pm 0.86$ & $0.90 \pm 0.07$ & $0 \pm 0.04$ & $98.5 \pm 0.64$ & $0.87 \pm 0.1$ & $0 \pm 0.04$ \\
\hline & 6 & $97.8 \pm 0.84$ & $0.89 \pm 0.07$ & $0.02 \pm 0.03$ & $87.3 \pm 6.5$ & $0.80 \pm 0.09$ & $\begin{array}{c}- \\
0.07 \pm 0.08\end{array}$ \\
\hline & 7 & $98.4 \pm 0.88$ & $0.86 \pm 0.05$ & $-0.02 \pm 0.03$ & $93.8 \pm 6.5$ & $0.85 \pm 0.08$ & $\begin{array}{c}- \\
0.03 \pm 0.09\end{array}$ \\
\hline & 8 & $97.4 \pm 0.83$ & $0.80 \pm 0.05$ & $-0.07 \pm 0.01$ & $91.9 \pm 8.7$ & $0.83 \pm 0.09$ & $0.04 \pm 0.06$ \\
\hline & CV & 4.9 & 6.7 & -197.8 & & & \\
\hline & LSD & 6.1 & 0.1 & 0.1 & & & \\
\hline \multirow[t]{6}{*}{ Root } & 0 & $97.6 \pm 0.86$ & $0.87 \pm 0.04$ & $0 \pm 0$ & $98.48 \pm 0.64$ & $0.87 \pm 0.12$ & $0 \pm 0$ \\
\hline & 6 & $97.8 \pm 0.83$ & $0.89 \pm 0.11$ & $0.02 \pm 0.04$ & $84.02 \pm 2.9$ & $0.39 \pm 0.1$ & $0.48 \pm 0.12$ \\
\hline & 7 & $98.4 \pm 0.88$ & $0.75 \pm 0.15$ & $-0.12 \pm 0.11$ & $87.54 \pm 4.2$ & $0.25 \pm 0.14$ & $-0.61 \pm 0.1$ \\
\hline & 8 & $97.4 \pm 0.83$ & $0.79 \pm 0.15$ & $-0.07 \pm 0.14$ & $86.06 \pm 3.4$ & $0.31 \pm 0.24$ & $\begin{array}{c}- \\
0.56 \pm 0.14\end{array}$ \\
\hline & $\mathrm{CV}$ & 10.7 & 20.2 & -52.8 & & & \\
\hline & LSD & 12.8 & 0.2 & 0.2 & & & \\
\hline
\end{tabular}

An asterisk represents a significantly greater value than the other accession at $5 \%(*), 1 \%(* *)$ and $0.1 \%(* * *)$ level. The difference between accessions was statistically analyzed by Tukey pair wise comparison (ANOVA). A hyphen (-) indicates that all pieces of the three tested tissues were withered, and value in parenthesis indicates that 1-2 pieces of the three tested tissues were withered.

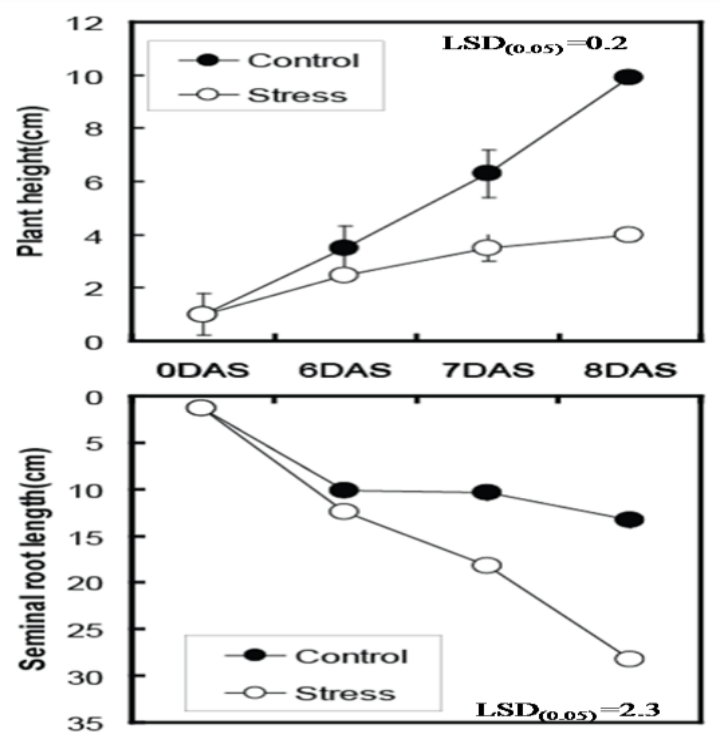

Figure 3. Influence of drought stress on leave and root growth of tef for $2,4,6$ and 8 days. Presented values for leaves and roots are the means of three replications. Vertical bars represent the SD. 
Transcriptome analysis of tef root tips in response to drought

The drought-responsive genes were identified by changes in the gene expression patterns of the three replicates; the two-fold difference in the ratio of drought: control transcript abundance and $p$-value less than 0.05 (Figure 4, Table 2). The scatter plot of data from three replications to compare the control and stressed transcripts showed that there is a linear relationship between most of the genes expressed under control and stressed samples. From the 176 differentially expressed genes, 77 have greater than two-fold changes, but 93 genes were down-regulated with a fold change of less than or equal to minus two. Lesser number of genes were up and down-regulated might be due to the low hybridization signal because of low homology between orthologous genes.

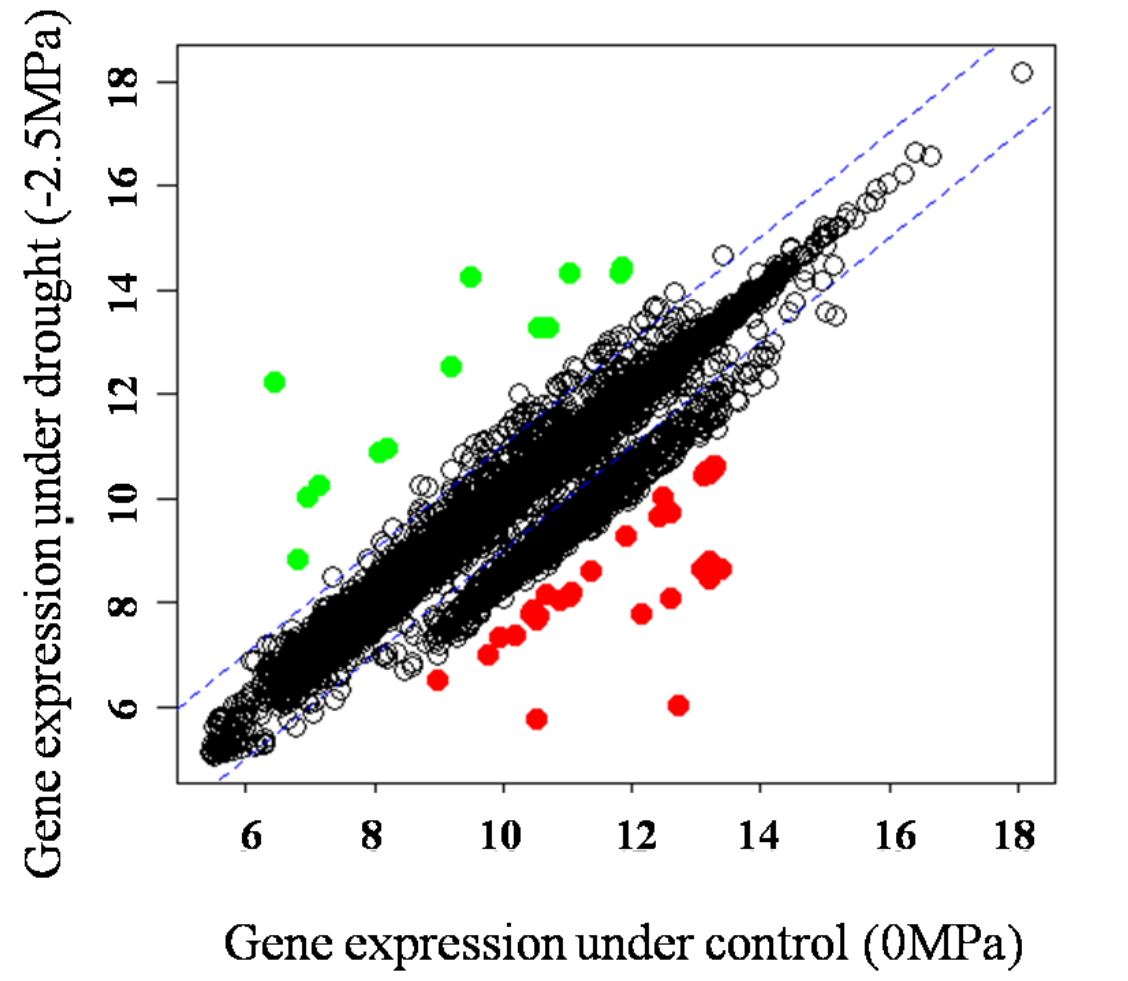

Figure 4. Scatter plot comparisons of microarray gene expression in drought-stressed $\mathrm{E}$. tef . The normalized expression value (signal) for each gene under well-watered (control) vs. drought-stress plotted for E. tef at -2.5 MPa leaf water potential samples (A).

Table2.Selected drought responsive genes in $O$ sativa highly hybridized resulted in up or down regulation of $E$. tef transcript (significant at 5\% level)

\begin{tabular}{|c|c|c|c|c|c|c|}
\hline ProbeName & $\begin{array}{l}\text { GeneNam } \\
\text { elSystema } \\
\text { ticName }\end{array}$ & Gene symbol & Locus tag & $\begin{array}{c}\text { Fol } \\
\text { d } \\
\text { Ch } \\
\text { an } \\
\text { ge }\end{array}$ & $\begin{array}{c}- \\
\text { Log } \\
\text { pva } \\
\text { I }\end{array}$ & Gene description \\
\hline A_71_P120462 & AK109080 & LOC4344714 & $\begin{array}{l}\text { OSNPB_08015970 } \\
0\end{array}$ & $\overline{-}$ & 4.2 & $\begin{array}{l}\text { AT-hook motif nuclear-localized } \\
\text { protein } 23\end{array}$ \\
\hline A_71_P113410 & AK067302 & LOC4333169 & $\begin{array}{l}\text { OSNPB_03042880 } \\
0\end{array}$ & - & 4.9 & Uncharacterized \\
\hline
\end{tabular}


Hewan/ Nig. J. Biotech. Vol. 36 Num. 2 : 167 - 187 (December 2019)

A_71_P103875 AK058902 LOC4329688

A_71_P126315

A_71_P120333

A_71_P110996

A_71_P102759

A_71_P104162

A_71_P125325

A_71_P102968

A_71_P123735

A_71_P126097

A_71_P106066

A_71_P126249

A_71_P104593

A_71_P106979

A_71_P106439

A_71_P119754

A_71_P122240

A_71_P105146

A_71_P118869

A_71_P124449

A_71_P114932

A_71_P121233

A_71_P109377

A_71_P125413

A_71_P102782

A_71_P102538

A_71_P121607
AK069006 LOC4352600

AK069943 LOC4344472

AK100257 LOC4337170

AK102031 LOC4327316

AK102271 LOC4331143

AK102853 LOC4350717

AK109457 LOC4324110

AK109491 LOC4349090

AK059940 LOC4352037

AK063459 LOC4329297

AK064505 LOC4351872

AK067496 LOC4329918

AK067772 LOC4330316

AK102091 LOC4330628

AK103321 LOC4344573

AK110546 LOC4347641

AK058851 LOC4329525

AK061900 LOC9270800

AK063047 LOC4328135

AK065359 LOC4339070

AK066884 LOC4346328

AK067103 LOC4331586

AK101774 LOC4350003

AK108736 LOC4325031

AK073493 LOC4325494

AK099503 LOC4347825
OSNPB_02056240

OSNPB_12057400

0

OSNPB_08010950

0

OSNPB_04064120

0

OSNPB_01019460

0

OSNPB_02081680

0

OSNPB_11055560

0

OSNPB_01068630

0

OSNPB_10051050

0

OSNPB_12040380

0

OSNPB_02046120

0

OSNPB_12024290

OSNPB 02060550

0

OSNPB_02067950

0

OSNPB_02073220

0

OSNPB_08012780

0

OSNPB_09052750

0

OSNPB_02052720

0

OSNPB_07051690

0

OSNPB_02012310

0

OSNPB_05047000

0

OSNPB_08056160

0

OSNPB_03014290

0

OSNPB_11019960

0

OSNPB_01089920

0

OSNPB_01076640

0

OSNPB_09055740 $\begin{array}{lll}- & 7.1 & \\ 4.4 & \text { ankyrin repeat protein SKIP35 }\end{array}$

2.94 .7 beta-galactosidase 11 -like

$2.94 .7(+)$-neomenthol dehydrogenase

$2.9 \quad 4.7$ Uncharacterized

2.9 4.7 U-box domain-containing protein 11

- 4.7 helicase-like transcription factor

$2.9 \quad 4.7$ CHR28

- 4.7 probable E3 ubiquitin-protein ligase

2.9 4.7 BAH1-like 1

- 4.7 probable calcium-binding protein

$\begin{array}{lll}2.9 & 4.7 \quad \mathrm{CML} 27\end{array}$

2.9

4.7 Uncharacterized

2.9

4.6 probable receptor-like

serine/threonine-protein kinase

2.94 .6 Uncharacterized

2.94 .6 Uncharacterized

2.9 4.6 RINT1-like protein MAG2L

2.9 4.6 Uncharacterized

2.9 4.6 anamorsin homolog 1-like

2.94 .6 protein CDI

2.94 .6 Unknown expressed protein

$2.8 \quad 4.4$ Uncharacterized

$2.8 \quad 4.4 \quad 50$ S ribosomal protein L31

2.8 $4.4 \quad$ Unknown expressed protein

- 4.4 glycine-rich RNA-binding protein 2,

$2.8 \quad 4.4$ mitochondrial

2.84 .4 Uncharacterized

- $\quad 4.4$ 50S ribosomal protein L28,

$2.8 \quad 4.4$ chloroplastic

2.8

4.4

indole-3-glycerol phosphate synthase, chloroplastic

28

4.4

anaphase-promoting complex subunit 15

2.7

fasciclin-like arabinogalactan protein

$4.8 \quad 13$

4.8 mitogen-activated protein kinase 14- 
Hewan/ Nig. J. Biotech. Vol. 36 Num. 2 : 167 - 187 (December 2019)

A_71_P100151

A_71_P106899

A_71_P115743

A_71_P110642

A_71_P102476

A_71_P103041

A_71_P121864

A_71_P110380

A_71_P112428

A_71_P102854

A_71_P114265

A_71_P103793

A_71_P103646

A_71_P122572

A_71_P115357

A_71_P105946

A_71_P102743

A_71_P114270

A_71_P127945

A_71_P128119

A_71_P125176

A_71_P108336

A_71_P119552

A_71_P117169

A_71_P111395
AK100105 LOC4327103

AK100401 LOC4328582

AK101156 LOC4340300

AK103022 LOC4333590

AK112105 LOC9270556

AK065358 LOC4324159

AK068829 LOC4347892

AK069970 LOC4332513

AK101611 LOC4336833

AK102203 LOC4324824

AK103819 LOC4339464

AK109718 LOC4327168

AK062051 LOC4326593

AK068391 LOC4346642

AK069632 LOC4337885

AK072940 LOC4328666

AK100090

LOC4324749

AK103672 LOC4339458

AK110168

LOC4326544

AK110386 LOC4329433

AK064740 LOC4350576

AK066383 LOC9266989

AK066544 LOC4342173

AK073271 LOC4340699

AK101488 LOC4334912
0

OSNPB_01025100

$2.7 \quad$ like OSNPB_02019210 0 OSNPB_06017920 0 OSNPB_03065090 0 OSNPB_01035420 0 OSNPB_01073350 0 OSNPB_09056800 0 OSNPB_03029280 0 OSNPB_04059270 0

OSNPB_01085450

0 OSNPB_05054010 0 OSNPB_01065980 0 OSNPB_01063300 0 OSNPB_09029400 0 OSNPB_05016060 0 OSNPB_02020370 0

OSNPB_01085650 0 OSNPB_05053950 0

OSNPB_01074220

0 OSNPB_02050490 0 OSNPB_11051280 0 OSNPB_03010005 0 OSNPB_07010210 0 OSNPB_06026430 0

OSNPB_04010630

2.7

2.7

2.7

2.7

2.7

4.8

$2.7 \quad 4.4$ like

2.7

2.7

2.7

2.7

2.7

Protein trigalactosyldiacylglycerol 4, chloroplastic

4.8 Uncharacterized

4.8 Uncharacterized 1-like

4.8 Unknown expressed protein

4.8 protein trichome birefringence-like 28

4.8 amino acid transporter AVT1C

4.8 lachrymatory-factor synthase

DNA annealing helicase and endonuclease ZRANB3

NADH dehydrogenase [ubiquinone] 1

- 4.8 alpha subcomplex subunit 9,

2.7 mitochondrial

2.7 4.8 classical arabinogalactan protein 9

-7.8
2.7

- 4.4 non-specific lipid-transfer protein 2-

4.4 protein DETOXIFICATION 29

$2.7 \quad 4.4 \quad$ Uncharacterized

$2.7 \quad 4.4$ ubiquitin receptor RAD23d

protein

2.74 .4 TRIGALACTOSYLDIACYLGLYCEROL 4, chloroplastic

2.7 4.4 flap endonuclease 1 -A-like

Filobasidiellaneoformans var.

2.7 4.4 neoformans translation elongation factor 2

4.4 F-box/kelch-repeat protein At1g67480

4.4 glutamine--tRNA ligase

4.4 SCAR-like protein 1

4.4 F-box/kelch-repeat protein At1g74510

2.7 4.4 protein transport protein Sec24C

- $\quad 4.4$ disease resistance protein PIK6-NP- 
Hewan/ Nig. J. Biotech. Vol. 36 Num. 2 : 167 - 187 (December 2019)

A_71_P110635

A_71_P112010

A_71_P109593

A_71_P102642

A_71_P105802

A_71_P126815

A_71_P123898

A_71_P111111

A_71_P116173

A_71_P112259

A_71_P106457

A_71_P117853

A_71_P111034

A_71_P119970

A_71_P117941

A_71_P117316

A_71_P110278

A_71_P117528

A_71_P119501

A_71_P118242

A_71_P124967

A_71_P124115

A_71_P124066

A_71_P110063

A_71_P107096

A_71_P105265

$\begin{array}{ll}\text { AK105583 } & \text { LOC4333158 } \\ & \text { LOC10727872 }\end{array}$

AK109273 8

AK109470 LOC4332731

AK059715 LOC4324964

AK063438 LOC4328135

AK068049 LOC4351356

AK070579 LOC4348282

AK101835 LOC4336102

AK102365 LOC4342018

AK062775 LOC4333169

AK064402 LOC4329874

AK067620 LOC4344339

AK102124 LOC4337380

AK103306 LOC4346187

AK106266 LOC4342464

AK109313 LOC4329438

AK061178 LOC4332206

AK064179 LOC4340325

AK065696 LOC4343831

AK069889 LOC4342267

AK072582 LOC4349984

AK106467 LOC4348087

AK107022 LOC4348241

AK058803 LOC4332352

AK066613 LOC4330727

AK069956 LOC4330113 OSNPB_03033170
0

OSNPB_03042590

$2.7 \quad$ like OSNPB_04065540 0 OSNPB_01089460 0 OSNPB_02012310 0 OSNPB_12012100 0 OSNPB_10020970 0 OSNPB_04046770 0 OSNPB_06070810 OSNPB_03042880 0 OSNPB_02059820 0 OSNPB_07068670 0 OSNPB_04067440 0 OSNPB_08054040 0 OSNPB_07016290 0 OSNPB_02050650 0 OSNPB_03024080 1 OSNPB_06018410 0 OSNPB_07060260 0 OSNPB_07011900 0 OSNPB_11019460 0 OSNPB_10014190 0 OSNPB_10019350 0

OSNPB_03026580 OSNPB_02074830 0 OSNPB_02064080 0

2.7

2.7

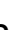

2.7

2.7

2.7

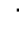

2.7

4.6

2.7

2.7

2.7

2.7

2.7
- 4.4 eukaryotic translation initiation factor

$2.7 \quad 4.4 \quad 2$ subunit alpha homolog

- 4.4 ubiquitin-like modifier-activating

$2.7 \quad 4.4$ enzyme 5

${ }_{2}^{-} \quad 4.4$ auxin-responsive protein SAUR32

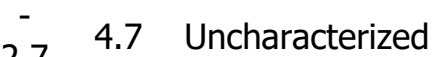

2.7 4.7 Uncharacterized

- 4.7 glucose-6-phosphate isomerase 1,

$2.7 \quad 4.7$ chloroplastic

2.7 4.7 Uncharacterized

- 4.7 G-type lectin S-receptor-like

$2.7 \quad 4.7$ serine/threonine-protein kinase

2.7 4.7 wall-associated receptor kinase 1

- 4.3 protein CHAPERONE-LIKE PROTEIN

$2.7 \quad 4.3 \quad$ OF POR1

2.7 4.3 Uncharacterized

chloroplastic import inner membrane translocase subunit HP30-2

4.3 WUSCHEL-related homeobox 9-like

4.3 Uncharacterized

4.3 Uncharacterized

4.3 ubiquitin-like modifier-activating

4.6 elongation factor 1 -alpha-like

B3 domain-containing protein

Os02g0598200-like

4.6 Uncharacterized

4.6 Uncharacterized

4.6 protein MAIN-LIKE 2

4.6 Uncharacterized

4.6 17kDa alpha-amylase/trypsin inhibitor

2.7 4.4 Uncharacterized

- 4.4 serine/arginine repetitive matrix

$2.7 \quad 4.4$ protein 1

-
2.7 4.4 ran-binding protein 1 homolog a 
Hewan/ Nig. J. Biotech. Vol. 36 Num. 2 : 167 - 187 (December 2019)

A_71_P121291 AK101010 LOC9266867

A_71_P126741

A_71_P121378

A_71_P104421

A_71_P109351

A_71_P108529

A_71_P117690

A_71_P105792

A_71_P103675

A_71_P109785

A_71_P115818

A_71_P128158

A_71_P110945

A_71_P100324

A_71_P105147

A_71_P104323

A_71_P110156

A_71_P112354

A_71_P110583

A_71_P106058

A_71_P123431

A_71_P126492

A_71_P123717

A_71_P118094

A_71_P107503

A_71_P119592

A_71_P114630
AK106509 LOC4351270

AK108589 LOC4344743 LOC10727524

AK109015 8

AK062506 LOC4331362

AK062977 LOC4331483

AK068356 LOC4331210

AK068761 LOC4330225

AK073433 LOC4325382

AK099818 LOC4332656

AK103068 LOC4340349

AK110434 LOC4339717

AK058848 LOC4335799

AK065125 LOC4325653

AK067722 LOC9267259

AK068122 LOC4331210

AK073459 LOC4333085

AK101902 LOC4335831

AK105818 LOC4332538

AK109318 LOC4329438

AK069758 LOC4348063

AK072652 LOC4351897

AK100196 LOC4325457

AK101955 LOC4343623

AK103085 LOC4334311

AK109447 LOC4343868

AK111471 LOC4338289
OSNPB_07068320

OSNPB_12010670

0

OSNPB_08016410

0

OSNPB_02059340

OSNPB 03011130

0

OSNPB_03012790

0

OSNPB_02082550

0

OSNPB_02066180

0

OSNPB_01095720

0

OSNPB_03031700

0

OSNPB_06018700

0

OSNPB_05057990

0

OSNPB_04041470

0

OSNPB_01018520

0

OSNPB_02052650

0

OSNPB_02082550

0

OSNPB_03040910

0

OSNPB_04042090

0

OSNPB_03029640

0

OSNPB_02050650

0

OSNPB_10013620

0

OSNPB_12025440

0

OSNPB_01014310

0

OSNPB_07056530

0

OSNPB_03078080

0

OSNPB_07060840

0

OSNPB_05028050 $\begin{array}{ccc}- & 4.4 & \\ 2.7 & & \end{array}$

- 4.7 Uncharacterized

$2.7 \quad 4.4$ probable methyltransferase PMT19

2.7 4.4 Uncharacterized

- 4.4 probable phospholipid hydroperoxide

$2.7 \quad 4.4 \quad$ glutathione peroxidase

2.7 4.4 cyclin-dependent kinase A-2-like

- 4.4 Bifunctionalaspartokinase/homoserine

2.74 .4 dehydrogenase 2, chloroplastic

- 4.4 mitochondrial proton/calcium

$2.7 \quad 4.4$ exchanger protein

$27 \quad 4.4$ Uncharacterized

-7
2.7 auxin transporter-like protein 1

- 4.4 dihydroceramide fatty acyl 2-

$2.7 \quad 4.4$ hydroxylase $\mathrm{FAH} 2$

$\begin{array}{lll}2.7 & 4.4 & \text { auxilin-related protein } 1\end{array}$

2.56 .0 photosystem I subunit $O$

2.56 .0 beta-1,4-mannosyl-glycoprotein 4-

$2.5 \quad 6.0$ beta-Nacetylglucosaminyltransferase

2.56 .0 rho GTPase-activating protein 5

$2.5 \quad 6.0 \quad$ Uncharacterized

$2.5 \quad 6.0 \quad$ Uncharacterized

$2.5 \quad 6.0 \quad$ Uncharacterized

$2.5 \quad 6.0$ probable carboxylesterase 15

2.56 .0 RNA-binding protein CP29B, $2.6 \quad 5.2$ mitogen-activated protein kinase

$2.6 \quad 5.2$ Uncharacterized

2.65 .2 mitochondrial substrate carrier family

$2.6 \quad 5.2$ monothiol glutaredoxin-S2-like

$2.6 \quad 5.2$ calcium-dependent protein kinase 21$\begin{array}{lll}2.6 & 5.2 & \text { like }\end{array}$

$2.6 \quad 5.2$ gallate 1-beta-glucosyltransferase

$2.6 \quad 5.2$ soluble inorganic pyrophosphatase 
Hewan/ Nig. J. Biotech. Vol. 36 Num. 2 : 167 - 187 (December 2019)

A_71_P110290

A_71_P107682

A_71_P124888

A_71_P104586

A_71_P119866

A_71_P123084

A_71_P118954

A_71_P103200

A_71_P111340

A_71_P125379

A_71_P104150

A_71_P111210

A_71_P113166

A_71_P123021

A_71_P118139

A_71_P128030

A_71_P120556

A_71_P117434

A_71_P107424

A_71_P126067

A_71_P114418

A_71_P104020

A_71_P107567

A_71_P128033

A_71_P101793

A_71_P111748
0

OSNPB_03024160

AK060019 LOC4332213

OSNPB 03017750

AK061464 LOC4331811 0

OSNPB_11053340

AK063652 LOC9270608

OSNPB_02015300

AK064473 LOC4328332 0

OSNPB_08054920

0

OSNPB_10044610

0

OSNPB_07012290

0

OSNPB_01094620

$\begin{array}{lll}\text { AK071060 LOC4325828 } & 0 \\ & & \text { OSNPB_04045050 }\end{array}$

$\begin{array}{lll}\text { AK071060 LOC4325828 } & \text { O } \\ & & \text { OSNPB_04045050 }\end{array}$

AK058975 LOC4335998 0

OSNPB_11015330

AK060118 LOC4349805

AK065136 LOC4329854 O

AK100967 LOC4335200

AK101116 LOC4336249

AK103655 LOC4349117

AK107633 LOC4342730

NPB 07021670

0

OSNPB_07068320

AK110267 LOC9266867 0

OSNPB_08041690

AK062863 LOC4345581 O

OSNPB_02056240

AK063377 LOC4329688 0

LOC11293822 OSNPB_03027670

$\begin{array}{lll}\text { AK063885 } 7 & 0\end{array}$

AK065165 LOC4352741 O

OSNPB_12060580

0

OSNPB_05056360

AK099313 LOC4339617 0

OSNPB_02079760

AK104474 LOC4331018 0

OSNPB_03037660

AK109412 LOC4332957 O

OSNPB 12010530

AK110273 LOC9269069 0

OSNPB_01086650

AK111757 LOC4325072 O

OSNPB_04055630

AK062772 LOC4336627 0
$2.6 \quad 4.7 \quad$ Uncharacterized

$2.6 \quad 4.7 \quad$ Uncharacterized

$2.6 \quad 4.7$ exosome complex component RRP41like

2.6 4.7 DNA polymerase alpha subunit B

$2.6 \quad 4.7$ dehydrodolichyl diphosphate synthase 6

2.64 .7 bromodomain-containing factor 2

2.6 4.7 probable alkaline/neutral invertase $\mathrm{F}$

$2.6 \quad 4.7 \quad$ Unknown expressed protein

$2.6 \quad 4.9 \quad$ Uncharacterized

$2.6 \quad 4.9 \quad$ Unknown expressed protein

2.64 .9 methylcrotonoyl-CoA carboxylase

2.6 subunit alpha, mitochondrial-like

$2.6 \quad 4.9 \quad$ Uncharacterized

2.64 .9 protein NRT1/ PTR FAMILY 4.5

$2.6 \quad 4.9 \quad$ Uncharacterized

$2.6 \quad 4.9 \quad$ Uncharacterized

$2.6 \quad 4.9 \quad$ NAC transcription factor 29

$\begin{array}{lll}2.7 & 5.1 & K(+) \\ & \text { efflux antiporter } 5\end{array}$

$2.75 .1 \quad$ cyclin-dependent kinase A-2-like

$2.7 \quad 5.1 \quad$ Uncharacterized

2.7 5.1 BURP domain-containing protein 3-

$2.7 \quad 5.1 \quad$ Uncharacterized

$2.7 \quad 5.1 \quad$ Uncharacterized

2.7 5.1 PHD finger protein ALFIN-LIKE 9-like

2.75 .1 protein CHUP1, chloroplastic

$2.7 \quad 4.8$ delta(14)-sterol reductase

2.7 5.0 Oryza sativa glutathione peroxidase 1 (GPX1) 
Hewan/ Nig. J. Biotech. Vol. 36 Num. 2 : 167 - 187 (December 2019)

A_71_P107943

A_71_P107609

A_71_P124577

A_71_P113689

A_71_P119849

A_71_P111324

A_71_P121341

A_71_P122196

A_71_P106957

A_71_P112363

A_71_P118271

A_71_P117346

A_71_P128236

A_71_P128274

A_71_P113288

A_71_P124567

A_71_P110906

A_71_P113574

A_71_P125669

A_71_P112718

A_71_P117818

A_71_P103769

A_71_P100337

A_71_P109704

A_71_P120608

A_71_P113554

A_71_P120282
AK068484 LOC4333501

AK068746 LOC4333878

AK072924 LOC4350916

AK099719 LOC9267958

AK101404 LOC4344441

AK109889 LOC4336181

AK058477 LOC4345657

AK068061 LOC4347311

AK072724 LOC4329681

AK073418 LOC4335786

AK101648 LOC4343803

AK108060 LOC4331157

AK110559 LOC9270256

AK110618 LOC4344309

AK067481 LOC4337526

AK070884 LOC4349916

AK100347 LOC4335990

AK100817 LOC4335199

AK101496 LOC9272227

AK102284 LOC4337089

AK109158 LOC4343876

AK110526 LOC4326871

AK071475 LOC4326040

AK060233 LOC4333169

AK059773 LOC9268297

AK061590 LOC4339442

AK063695 LOC4344519
OSNPB_03062670

0

OSNPB_03071060

0

OSNPB_11061490

0

OSNPB_05014350

0

OSNPB_08010480

0

OSNPB_04048090

0

OSNPB_08043430

0

OSNPB_09046560

0

OSNPB_02055850

0

OSNPB_04041290

0

OSNPB_07059830

0

OSNPB_02081890

OSNPB_01069890

OSNPB 07068200

0

OSNPB_05010140

0

OSNPB_11017540

0

OSNPB_04044950

0

OSNPB_04022160

0

OSNPB_12046730

0

OSNPB_04062930

0

OSNPB_07061170

0

OSNPB_01054270

0

OSNPB_01012110

0

OSNPB_03042880

0

OSNPB_08047020

0

OSNPB_05053570

0

OSNPB_08011680
$2.7 \quad 5.0 \quad$ Uncharacterized

2.7 5.0 probable lipid phosphate phosphatase beta

$2.7 \quad 5.0$ transcription initiation factor TFIID subunit 15b

$2.7 \quad 5.0 \quad$ YTH domain-containing family protein 2

$2.7 \quad 5.0$ arginase 1 , mitochondrial-like

$2.7 \quad 5.0 \quad$ Unknown expressed protein

2.8 5.2 malate dehydrogenase, chloroplastic

$2.8 \quad 5.2 \quad$ Uncharacterized

$2.8 \quad 5.2 \quad$ Uncharacterized

$2.8 \quad 5.2 \quad$ Uncharacterized

$2.8 \quad 5.2$ zinc finger $\mathrm{CCHC}$ domain-containing

$2.8 \quad 5.2 \quad$ F-box protein SKIP23

$2.8 \quad 5.2$ nascent polypeptide-associated

5.2 complex subunit alpha-like protein 2

$2.8 \quad 5.2$ protein PYRICULARIA ORYZAE

RESISTANCE 21-like

$2.8 \quad 5.2$ TNF receptor-associated factor 6

2.8 5.2 NAC domain-containing protein 48-

2.85 .2 protein FLX-like 2

$2.8 \quad 5.2 \quad$ Uncharacterized

$2.8 \quad 5.2$ transducin beta-like protein 3

$2.8 \quad 5.2$ probable isoprenylcysteine alphacarbonyl methylesterase ICMEL1

$2.8 \quad 5.2$ rust resistance kinase $\operatorname{Lr} 10$

$2.8 \quad 5.2 \quad$ Uncharacterized

3.16 .6 ankyrin repeat protein SKIP35

$3.1 \quad 7.7$ Uncharacterized

3.3 5.2 alpha carbonic anhydrase 7

3.35 .2 polyadenylate-binding protein RBP45

3.3 5.2 exosome complex component RRP41- 
Hewan/ Nig. J. Biotech. Vol. 36 Num. 2 : 167 - 187 (December 2019)

\begin{tabular}{|c|c|c|c|c|c|c|}
\hline & & & 0 & & & like \\
\hline A_71_P109622 & AK066412 & LOC4334569 & $\begin{array}{l}\text { OSNPB_03081690 } \\
0\end{array}$ & 3.3 & 5.2 & potassium transporter 22-like \\
\hline A_71_P111475 & AK068782 & LOC4336282 & $\begin{array}{l}\text { OSNPB_04049680 } \\
0\end{array}$ & 3.3 & 5.2 & Uncharacterized \\
\hline A_71_P119110 & AK069186 & LOC4343863 & $\begin{array}{l}\text { OSNPB_07060770 } \\
0\end{array}$ & 3.3 & 5.2 & Uncharacterized \\
\hline A_71_P101086 & AK069974 & LOC4327340 & $\begin{array}{l}\text { OSNPB_01019890 } \\
0\end{array}$ & 3.3 & 5.2 & $\begin{array}{l}\text { heavy metal-associated isoprenylated } \\
\text { plant protein } 7\end{array}$ \\
\hline A_71_P125732 & AK101059 & LOC4352458 & OSNPB_12054810 & 3.3 & 5.2 & condensin-2 complex subunit D3 \\
\hline A_71_P104256 & AK107997 & LOC4331157 & OSNPB_02081890 & 3.3 & 5.2 & Uncharacterized \\
\hline A_71_P120258 & AK059812 & LOC4344519 & $\begin{array}{l}\text { OSNPB_08011680 } \\
0\end{array}$ & 4.5 & 4.0 & Uncharacterized \\
\hline A_71_P120991 & AK065015 & LOC4344674 & OSNPB_08015270 & 4.8 & 9.8 & sphingoid long-chain bases kinase 1 \\
\hline A_71_P111306 & AK105252 & LOC4333169 & OSNPB_03042880 & 5.8 & 7.4 & Uncharacterized \\
\hline A_71_P105174 & AK073100 & LOC4330420 & $\begin{array}{l}\text { OSNPB_02069880 } \\
0 \\
\text { OSNPB_07065980 }\end{array}$ & 8.5 & 7.9 & probable WRKY transcription factor 14 \\
\hline A_71_P118665 & AK107155 & LOC4344172 & $\begin{array}{l}0 \\
\text { OSNPB_07065980 }\end{array}$ & $\begin{array}{l}8.5 \\
12 .\end{array}$ & 7.9 & E3 ubiquitin-protein ligase DIS1-like \\
\hline A_71_P110167 & AK100651 & LOC4344172 & $\begin{array}{l}0 \\
\text { OSNPB_06050730 }\end{array}$ & 5 & 4.0 & $\begin{array}{l}\text { E3 ubiquitin-protein ligase DIS1-like } \\
\text { BTB/POZ domain-containing protein }\end{array}$ \\
\hline A_71_P116544 & AK111324 & LOC4341136 & $\begin{array}{l}0 \\
\text { OSNPB_03033270 }\end{array}$ & $\begin{array}{l}6.3 \\
12 .\end{array}$ & 4.8 & $\begin{array}{l}\text { POB1 } \\
\text { ABC transporter I family member } 6 \text {, }\end{array}$ \\
\hline A_71_P110549 & AK072820 & LOC4332739 & $\begin{array}{l}0 \\
\text { OSNPB } 01070750\end{array}$ & 5 & 5.8 & chloroplastic \\
\hline A_71_P102603 & AK100208 & LOC4327679 & 0 & 9.4 & 6.7 & bHLH transcription factor \\
\hline
\end{tabular}

Functional Characterization of droughtresponsive genes

The differentially expressed genes were classified into functional categories. The functional annotation of these genes is based on sequences which match to other sequences in the GenBank using BLAST analysis. The result is set with the threshold of expectation value less than 10-10. Among the 171 differentially expressed transcripts, 57 belong to genes with unknown functions. The dissection of the expressed gene profile of tef under drought stress showed that most of the transcripts (93) were down-regulated (Figure 4). On the other hand, 77 transcripts were up-regulated under drought stress. Those differentially expressed genes between drought-stressed and wellirrigated tef root plant (77 up-regulated and 93 down-regulated) were identified by Linear Models for Microarray (LIMMA) (adjusted pvalue $\leq 0.05$; with fold change (FC) of $|2|$ ). 


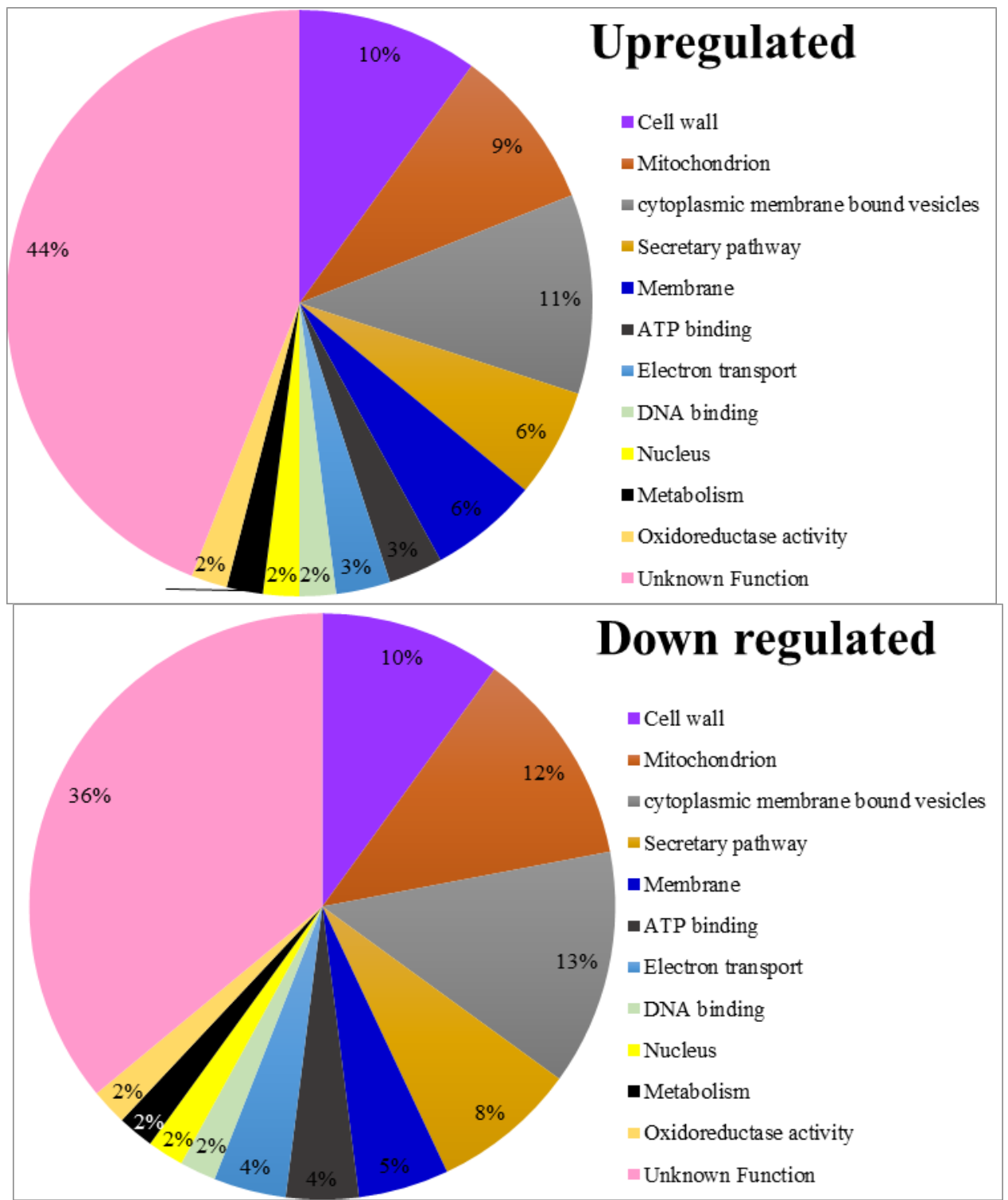

Figure 5. Distribution of drought responsive genes in E. tef for their functional classes. Percentage of drought responsive genes in the various functional categories; Up-regulated (top) and Down- regulated (bottom).

The resulting unregulated and down-regulated genes were further analyzed using the Gene Ontology (GO) Enrichment analysis to identify their molecular function. The majority of the transcripts belong to the unknown function $44 \%$ and $36 \%$ for up-regulated and down-regulated genes, respectively. The rest were categorized into cell wall $(10 \%)$, Mitochondrion ( $9 \%$ and $12 \%)$, cytoplasm membrane-bound vesicles $(11 \%$ and $13 \%)$, secretary pathway (6\% and $8 \%)$, membrane (5\% and 6\%), ATP binding
( $3 \%$ and $4 \%$ ), electron transport ( $3 \%$ and $4 \%$ ), cellular process $(21 \%)$, localization $(7 \%)$, DNA binding (2\%), Nucleus (2\%), metabolism(2\%), and Oxidoreductase activity (2\%), were for upregulated and down-regulated genes, respectively (Figure5).

RT-PCR, Real-Time Quantitative PCR and Northern blot analysis of highly differentially expressed transcript 
Preliminary assessment of gene expression patterns under the normal control (wellirrigated) and drought stress in tef root (for 2, 4, 6, and 8) was performed for WRKY gene (Table 2) by quantitative RT-PCR, Real-time Quantitative PCR and Northern blot (Figure 6). The expression patterns under well irrigated and drought stress conditions differed significantly (LSD0.05 = 0.49). This gene was not expressed at all under the well-irrigated condition as evidenced in expression analysis.. This implies the gene was significantly induced by drought in the roots. (a)

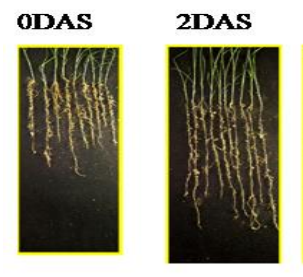

(c)

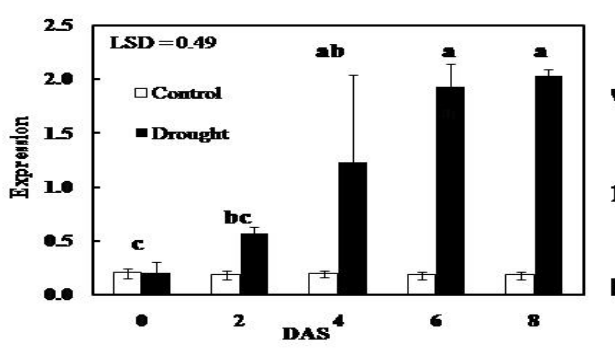

(b)

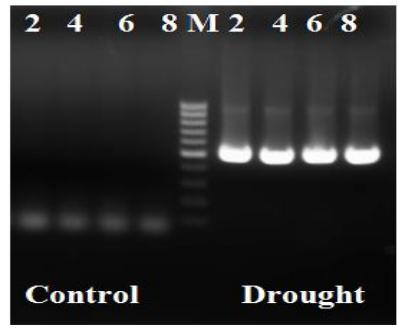

(d)

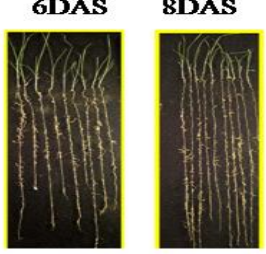

4DAS

GDAS

SDAS

C

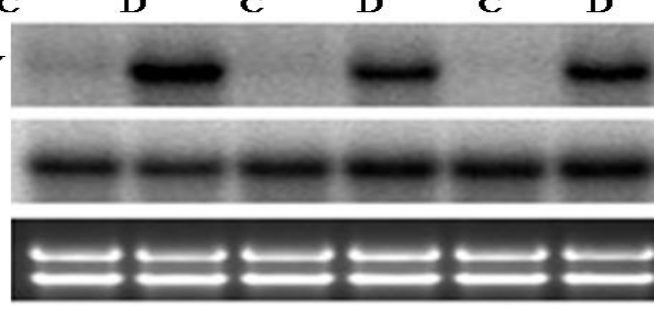

Figure 6. (a) The elongation of tef root (scale bar $35 \mathrm{~cm}$ ) under drought stress compared to control from 0 to 8 DAS (days after stress). (b) RT-PCR analysis of tef's root WRKY gene after treatment for 2,4,6 and 8 days under drought stress. (c) Effect of drought stress on gene expression of WRKY in roots of tef. (d) Effect of drought stress on WRKY gene in tef root cells. Total RNAs were isolated from tef root which grow under drought stress for 4, 6 and 8 days. Total RNAs (10 $\mu \mathrm{g}$ each) were electrophoreses on an agarose gel, transferred onto a membrane and were probed with 32P-labeled isoform specific DNA fragments. The lower panel shows the quantification of ethidium bromide-stained total RNA after 4, 6 and 8 days after drought stress. Symbols, C and D indicate the well irrigated and drought stressed sample, respectively. that the levels of the TDFs are increased or not affected by the treatments, respectively. To show equal amount of RNA for all used for all experiment, $18 \mathrm{~S}$ ribosome cDNA is control.

\section{Discussion}

Well irrigated and drought-stressed Kaye Murri showed significant variation in terms of shoot and root RWC, OP and OA suggest that drought stress tolerance mechanism by $\mathrm{OA}$ is operating on tef.
The drought-stressed plants had higher OA value and elongated root length, which indicated that some drought tolerance mechanism is operating by $\mathrm{OA}$ and deep root system under drought stress. This implies that the two traits can be studied at the molecular level to elucidate the tolerant mechanism of tef under drought stress. The increased seminal root length in tef under the drought stress is due to 
the shift in elongation of the shoot as compared to the well-irrigated leaf sample (Figure 3).

To unravel the transcripts related to the elongation of the root in tef, rice microarray chips with the known gene was used in this experiment. Rice is a model plant where extensive studies related to drought has been carried out (Moon and Jung, 2014; Moon et al., 2014a, 2018; Ramamoorthy et al., 2008). Multiple whole-genome sequences of rice and transcription studies and other molecular tools are available for this crop. Tef is one of the most drought-tolerant cereals, providing a useful platform to understand the mystery of root elongation under drought stress. Since many of the monocot genomes had high synteny (Choe et al., 2018), it is feasible to use rice chips to do hybridization with tef RNAs. However, from the hybridization of tef and rice transcripts, only 171 genes are differentially regulated. This might be the low homology of the rice orthologs to tef RNA.

Several ABC transporter family members are upregulated in tef root under drought stress. This transcript is essential in transporting compounds which are important in drought adaptation (Lane et al., 2016). The larger number of $A B C$ transporter genes are important in their ability to sequester and transport foreign chemicals and compound to protect the plant under drought stress (Hwang et al., 2016; Moon et al., 2014b). Basic helix-loop-helix (BHLH) transcription factor is also up-regulated in drought-stressed tef root. This transcription factor is responsible for the initiation of root development in plants (Schlereth et al., 2010). This involves the embryonic root signal for initiation of root elongation in tef root under drought stress.

However, WRKY transcription factor 14 is highly up regulated under drought stress. The role of WRKY transcription factors has been studied by many researchers on many crop plants under abiotic stress (Dong et al., 2003; Eulgem and Somssich, 2007; Eulgem et al., 2000; Mangelsen et al., 2008; Pandey and Somssich, 2009; Ren et al., 2010; Ross et al., 2007; Rushton et al., 2010; Shen et al., 2012). The expression of this transcription factor contributes to the various signaling pathways in plants. The translated protein regulates different functions as a negative or positive regulator. The up-regulation of this gene under drought stress and its confirmation by real-time and the Northern blot analysis indicate that it is involved in various regulatory functions.

We also observed that there is the down regulation of important transcription factors like CCHC-type zinc finger protein, GTPase-activating protein, BTB/POZ, and carbonic anhydrase protein under the drought-stressed root of tef. Gene regulation involves regulation of cis-acting transcription factors like $\mathrm{CCHC}$ both in DNA and RNA (Yang et al., 2017). The GAF BTB/POZ domain has also contributed to interactions with non-BTB/POZ proteins which reduced programmed cell death, and is an indication of the negative regulation of plant immune pathway (Orosa et al., 2017). Mitochondrial genes were also down-regulated (Table 1). The biosynthesis and morphological regulation of mitochondria were highly affected by the gene carnitine (Piemontese et al., 2017). This protein was involved in the metabolic pathways to regulate plants under drought stress (Rao et al., 2017). GTP binding proteins are up-regulated under drought stress and are involved in the root hair formation (Wang et al., 2016). In tef root, these genes were up-regulated and the morphology of tef roots under drought stress had less root hair development (Figure 1, Figure 6). Carbonic anhydrase plays a major role in all photosynthetic organism (DiMario et al., 2017) and is involved in the synthesis of lipid molecules in the plant (Ludwig, 2016). It seems that multiple genes of the Carbonic anhydrase are involved in the conversion of lipid in the root cell to facilitate the energy biosynthesis under drought stress; thus, facilitating the root elongation process by fueling for an energy source.

The molecular function of down-regulated genes includes transcription factor, hydrolyzing activity, RNA binding, transmembrane transporter, enzyme inhibiting, oxidoreductase and DNA binding activity (Table 2). TCP encodes plantspecific transcription factors like Transcription factor PCF8. Researches indicated that the down-regulation of PCF8 results in an increased tolerance towards abiotic stress (Yang et al., 2013). Membrane-anchored ubiquitin-fold 
protein 3 is involved in all biological process of eukaryotic plants. Mostly, E3 ligase binds to this protein and is involved in the regulation, production, and signaling of plant hormones (Nagels Durand et al., 2016). BTB/POZ PROTEIN 1 is involved in the regulation of crown rootless gene (CRL3) (Yu et al., 2016). The fact that this gene is down regulated in tef indicates its major involvements in delaying the crown root formation while facilitating seminal root elongation. Thus, the morphology of tef root is elongated seminal root with a few crown root formations.

\section{Conclusion}

Tef responds to drought by elongating the seminal root. One hundred seventy-six (176) differentially expressed transcripts were identified in the roots of the tef plants, under drought and well-irrigated conditions. The differentially regulated transcriptsconfirm the presence of key regulatory elements controlling the elongation of root related to the drought response. Extensive responsive transcripts are up-regulated under drought stress to sense the amount of water in the soil for proper growth and development. Transcripts linked to biosynthesis are expressed in response to drought stress. Thus, this transcriptome analysis allowed us to find putative targets for further functional investigation of tef root under drought stress. Further studies are essential to characterize the molecular functions of root and leaf transcripts under drought stress. Thus, the information would give us a better understanding to unravel the adaptation of tef under drought specific environmental conditions.

\section{Acknowledgments}

This research was supported by Japan Ministry of Agriculture, Education and Culture project "crop breeding." We would like to extend our acknowledgment to the ministry.

\section{References}

Abraha M., Shimelis $H$, Laing $M$, and Assefa $K$ (2016). Performance of Tef [(Zucc.) Trotter] Genotypes for Yield and Yield Components Under Drought-Stressed and Non-Stressed Conditions. Crop Sci. 56, 1799-1806.
Admas S, and Belay G (2011). Droughtresistance traits variability in Eragrostis tef $\mathrm{X}$ Eragrostis pilosa recombinant inbred lines. Afr. J. Agric. Res. 6, 3755-3761.

Assefa K, Yu JK, Zeid M, Belay G, Tefera H, and Sorrells, ME (2011). Breeding tef [Eragrostistef (Zucc.) trotter]: conventional and molecular approaches. Plant Breed. 130, 1-9.

Ayele M (1999). Genetic diversity in tef (Eragrostis tef (zucc) Trotter) for osmotic adjustment, root traits, and Amplified Fragment Length Polymorphism. Texas Tech University.

Belay G, Tefera H, Getachew A, Assefa K, and Metaferia G (2008). Highly client-oriented breeding with farmer participation in the Ethiopian cereal tef [Eragrostis tef (Zucc.) Trotter]. Afr. J. Agric. Res. 3, 022-028.

BelayG, Zemede A, Assefa K, Metaferia G, and Tefera H (2009). Seed size effect on grain weight and agronomic performance of tef [Eragrostis tef (Zucc.) Trotter]. Afr. J. Agric. Res. 4, 836-839.

Cannarozzi G, Plaza-Wüthrich S, Esfeld K. Larti S, Wilson YS, Girma D, de Castro E, Chanyalew S, Blösch R, FarinelliL,. (2014). Genome and transcriptome sequencing identifies breeding targets in the orphan crop tef (Eragrostis tef). BMC Genomics 15, 581.

Choe, J., Kim, J.-E., Lee, B.-W., Lee, J.H., Nam, M., Park, Y.-I., and Jo, S.-H. (2018). A comparative synteny analysis tool for targetgene SNP marker discovery: connecting genomics data to breeding in Solanaceae. Database 2018.

Degu HD, Ohta M, and Fujimura T (2008). Drought Tolerance of Eragrostis tef and Development of Roots. Int. J. Plant Sci. 169, 768-775.

Degu, HD, and Fujimura T (2010). Mapping QTLs Related to Plant Height and Root Development of Eragrostis tef under Drought. J. Agric. Sci. 2, 62.

DiMario RJ, Clayton H, Mukherjee A, Ludwig M, and Moroney JV (2017). Plant Carbonic 
Anhydrases: Structures, Locations, Evolution, and Physiological Roles. Mol. Plant 10, 30-46.

Dong J, Chen C, and Chen Z (2003). Expression profiles of the Arabidopsis WRKY gene super family during plant defense response. Plant Mol. Biol. 51, 21-37.

Eulgem T, and Somssich IE (2007). Networks of WRKY transcription factors in defense signaling. Curr. Opin. Plant Biol. 10, 366-371.

Eulgem T, Rushton PJ, Robatzek $\mathrm{S}$, and Somssich IE (2000). The WRKY superfamily of plant transcription factors. Trends Plant Sci. 5, 199-206.

Hailesillasie $H$, Araya A., Habtu $S$, Meles KG, Gebru G, Kisekka I, Girma A, HadguKM, and Foste, AJ (2016). Exploring optimal farm resources management strategy for Quncho-teff (Eragrostis tef (Zucc.) Trotter) using AquaCrop model. Agric. Water Manag. 178, 148-158.

Hwang JU, Song WY, Hong D, Ko D, Yamaoka Y, Jang S, Yim S, Lee E, Khare D, Kim K, (2016). Plant ABC Transporters Enable Many Unique Aspects of a Terrestrial Plant's Lifestyle. Mol. Plant 9, 338-355.

Lane TS, Rempe CS, Davitt J, Staton ME, Peng $Y$, Soltis D, Melkonian M, Deyholos M, Leebens Mack JH, Chase M, (2016). Diversity of ABC transporter genes across the plant kingdom and their potential utility in biotechnology. BMC Biotechnol. 16, 47.

Ludwig M (2016). Evolution of carbonic anhydrase in C 4 plants. Curr. Opin. Plant Biol. $31,16-22$.

Mangelsen E, Kilian J, Berendzen KW, Kolukisaoglu ÜH., Harter $\mathrm{K}$, Jansson $\mathrm{C}$, and Wanke $D(2008)$. Phylogenetic and comparative gene expression analysis of barley (Hordeum vulgare) WRKY transcription factor family reveals putatively retained functions between monocots and dicots. BMC Genomics 9, 194.

Maruyama K, Yamaguchi-Shinozaki K., and Shinozaki K. (2014). Gene expression profiling using DNA microarrays. Arab. Protoc. 381-391.
McCouch SR., Symbolization C (Committee on G., Linkage, N. and, and Cooperative) RG (2008). Gene Nomenclature System for Rice. Rice 1, 72-84.

Mi $\mathrm{H}$, Poudel S, Muruganujan A., Casagrande JT., and Thomas PD (2016). PANTHER version 10: expanded protein families and functions, and analysis tools. Nucleic Acids Res. 44, D336342.

Moon S, and Jung K.H. (2014). Genome-wide expression analysis of rice $A B C$ transporter family across spatio-temporal samples and in response to abiotic stresses. J. Plant Physiol. $171,1276-1288$.

Moon S, Jung, K.H, and others (2014a). Genome-wide expression analysis of rice $A B C$ transporter family across spatio-temporal samples and in response to abiotic stresses. J. Plant Physiol. 171, 1276-1288.

Moon, S, Jung, KH, and others (2014b). Genome-wide expression analysis of rice $A B C$ transporter family across spatio-temporal samples and in response to abiotic stresses. J. Plant Physiol. 171, 1276-1288.

Moon S, Chandran AN, An G, Lee C, and Jung, $\mathrm{KH}$. (2018). Genome-wide analysis of root hairpreferential genes in rice. Rice 11, 48.

Smyth GK., Ritchie M, Thorne N, and Wettenhall J (2005). LIMMA: linear models for microarray data. In Bioinformatics and Computational Biology Solutions Using $\mathrm{R}$ and Bioconductor. Statistics for Biology and Health.

Nagels ., Pauwels L, and Goossens A. (2016). The Ubiquitin System and Jasmonate Signaling. Plants 5, 6 .

Orosa B, He Q, Mesmar J, Gilroy, EM, McLellan $\mathrm{H}$, Yang C, Craig A, Bailey M, Zhang C, Moore JD, (2017). BTB-BACK Domain Protein POB1 Suppresses Immune Cell Death by Targeting Ubiquitin E3 ligase PUB17 for Degradation. PLOS Genet. 13, e1006540.

Pandey SP, and Somssich IE (2009). The role of WRKY transcription factors in plant immunity. Plant Physiol. 150, 1648-1655. 
Piemontese L, Cerchia C, Laghezza A, Ziccardi P, SblanoS, Tortorella P, Iacobazzi V, Infantino V, Convertini P, Dal Piaz, F, (2017). New diphenylmethane derivatives as peroxisome proliferator-activated receptor alpha/gamma dual agonists endowed with anti-proliferative effects and mitochondrial activity. Eur. J. Med. Chem. 127, 379-397.

Plaza S, Cannarozzi GM, and Tadele Z (2013). Genetic and phenotypic diversity in selected genotypes of tef [Eragrostistef (Zucc.)] Trotter. Afr. J. Agric. Res. 8, 1041-1049.

Ramamoorthy R. Jiang, S, Kumar N, Venkatesh PN, and Ramachandran S (2008). A Comprehensive Transcriptional Profiling of the WRKY Gene Family in Rice Under Various Abiotic and Phytohormone Treatments. Plant Cell Physiol. 49, 865-879.

Rao RP, Salvato F, Thal B, Eubel $H$, Thelen JJ, and Møller IM (2017). The proteome of higher plant mitochondria. Mitochondrion 33, 22-37.

Ren $X$, Chen Z, Liu Y, Zhang $H$, Zhang $M$, Liu Q, Hong $X$, Zhu JK, and Gong $Z$ (2010). ABO3, a WRKY transcription factor, mediates plant responses to abscisic acid and drought tolerance in Arabidopsis. Plant J. 63, 417-429.

Ritchie ME, Phipson B, Wu D, HuY, Law CW, Shi W, and Smyth GK. (2015). limma powers differential expression analyses for RNAsequencing and microarray studies. Nucleic Acids Res. 43,e47.

Ross CA, Liu Y, and Shen QJ (2007). The WRKY gene family in rice (Oryza sativa). J. Integr. Plant Biol. 49, 827-842.

Rushton PJ, Somssich IE, Ringler P, and She, QJ (2010). WRKY transcription factors. Trends Plant Sci. 15, 247-258.

Sato $Y$, Takehisa $H$, Kamatsuki K., Minami $H$, Namiki N, Ikawa $H$, Ohyanagi $H$, Sugimoto $K$,
Antonio BA, and Nagamura, Y (2013). RiceXPro Version 3.0: expanding the informatics resource for rice transcriptome. Nucleic Acids Res. 41, D1206-D1213.

Schlereth A, Möller B, Liu, W, Kientz M, Flipse J, Rademacher $E H$, Schmid $M$, Jürgens $G$, and Weijers D (2010). MONOPTEROS controls embryonic root initiation by regulating a mobile transcription factor. Nature 464, 913-916.

Shen $\mathrm{H}$, Liu C, Zhang Y, Meng X, Zhou X, Chu C, and Wang $X$ (2012). OsWRKY30 is activated by MAP kinases to confer drought tolerance in rice. Plant Mol. Biol. 80, 241-253.

SU SL, Singh DN, and Baghini MS (2014). A critical review of soil moisture measurement. Measurement 54, 92-105.

R Core Team (2018). R: A language and environment for statistical computing. $\mathrm{R}$ Foundation for Statistical Computing, Vienna, Austria. URL URL https://www.R-project.org/

Wang $H$, Lan $P$, and Shen RF (2016). Integration of transcriptomic and proteomic analysis towards understanding the systems biology of root hairs. Proteomics. 16: 877-893.

Yang C, Li D, Mao D, Liu X, Ji C, Li X, Zhao X, Cheng $Z$, Chen $C$, and Zhu L (2013). Overexpression of microRNA319 impacts leaf morphogenesis and leads to enhanced cold tolerance in rice ( Oryza sativa L.): Rice miR319 and cold response. Plant Cell Environ. 36, 22072218.

Yang F, Hsu P, Lee SD, Yang W, Hoskinson D, Xu W, Moore C, and Varani G (2017). The C terminus of Pcf11 forms a novel zinc-finger structure that plays an essential role in mRNA 3'-end processing. RNA 23, 98-107.

Yu, Gutjahr Li C, and Hochholdinger F (2016). Genetic control of lateral root formation in cereals. Trends in Plant Sci. 21, 951-961. 